\title{
Primary choroidal and cutaneous melanomas, bilateral choroidal melanomas, and familial occurrence of melanomas
}

\author{
J. A. OOSTERHUIS, ${ }^{1}$ L. N. WENT, ${ }^{2}$ AND H. T. LYNCH ${ }^{3}$
}

From the Departments of ${ }^{1}$ Ophthalmology and ${ }^{2}$ Human Genetics, Leiden University Medical Centre, The Netherlands, and the ${ }^{3}$ Department of Preventive Medicine and Public Health, Creighton University School of Medicine, Omaha, Nebraska, USA

SUMMARY The medical history of a patient with a familial atypical multiple mole melanoma syndrome revealed a combination of rare findings: occurrence of a melanoma in both eyes, development of 3 separate skin melanomas, and occurrence of other malignancies in the family. Another patient developed a choroidal and a skin melanoma, but there were no known malignancies in the family. A third patient with a choroidal melanoma had a mother with an ethmoidal melanoma.

The occurrence of primary malignant melanomas of the choroid and skin in the same patient is a rare phenomenon. In this paper the occurrence of both a primary choroidal melanoma and a primary cutaneous melanoma in 2 patients is reported. One of these patients had choroidal melanomas bilaterally and multiple cutaneous melanomas. The family study of this patient, described extensively elsewhere, provides evidence for the presence of the familial atypical multiple mole melanoma (FAMMM) syndrome $^{12}$ also referred to as B-K mole syndrome. ${ }^{3}$ In a third patient with a choroidal melanoma the mother had had a melanoma originating from the ethmoidal sinus.

\section{Case reports}

\section{CASE 1}

A 57-year-old man was referred to our clinic in May 1978 for evaluation of an intraocular mass in his right eye. His medical history was significant in that a tumour with a small satellite lesion had been removed from the scalp at the age of 53; both proved to be malignant melanomas. At the age of 54 one melanoma was excised from the skin of his right shoulder and another from the gluteal region.

Correspondence to Prof. J. A. Oosterhuis, Afdeling Oogheelkunde, Academisch Ziekenhuis, Rijnsburgerweg 10, 2333AA Leiden. The Netherlands.
On admission visual acuity was $1 / 60$ for the right eye and $6 / 6$ for the left eye. Ophthalmoscopy revealed an elevated, darkly pigmented, solid choroidal mass arising from the temporal equatorial region in the right eye. It measured approximately 13 $\mathrm{mm}$ in diameter and $8 \mathrm{~mm}$ in elevation. At that time the ocular media of the left eye were clear, and on ophthalmoscopy no abnormalities were observed in this eye. Fluorescein angiography showed an early mottled fluorescence and late diffuse staining of the tumour. A 48-hour ${ }^{32} \mathrm{P}$-uptake test was strongly positive, $+389 \%$, which is far above the critical level of $+60 \%$. A thorough medical examination for metastatic disease (including chest $x$-ray, liver function studies, and a liver scintigram) was negative. The clinical diagnosis was malignant melanoma of the choroid. Histological examination after enucleation confirmed that the tumour was a malignant melanoma of the epithelioid cell type which had already invaded halfway into the sclera.

Eight months after enucleation of the right eye the patient complained of blurred vision of his left eye. Within one day corrected visual acuity dropped from $6 / 6$ to $5 / 60$. Ophthalmoscopy revealed a rapidly spreading retinal detachment, becoming subtotal. At the lower periphery a tumour with a diameter of 10 $\mathrm{mm}$, an elevation of $8 \mathrm{~mm}$, and relatively little pigment was visible. Ultrasonography and a positive ${ }^{32} \mathrm{P}$-uptake test of $+181 \%$ supported the clinical diagnosis of malignant melanoma of the choroid. 
After enucleation the histological examination confirmed the diagnosis. The tumour contained mainly epithelioid cells which had penetrated through Bruch's membrane but had not invaded the sclera. The extensive medical examination was repeated. This time the chest $x$-ray tomogram showed 3 lesions indicative of metastases.

In subsequent months the general condition gradually deteriorated due to metastatic spreading. Nine months after enucleation of the second eye the patient died.

This patient was a member of a family in which the FAMMM syndrome occurred. This family has been studied extensively ${ }^{4}$ (in the pedigree from that publication he is III-8). In an earlier report on inherited malignant melanomas ${ }^{1}$ he appears as IV-16 of pedigree 2 .

CASE 2

A 52-year-old man was referred because of a $4 \mathrm{D}$ prominent tumour with the aspect of a choroidal melanoma, measuring $5 \mathrm{~mm}$ in diameter and located superior to the posterior pole. Corrected visual acuity was $0 \cdot 6$. Fluorescein angiography showed a pattern typical of choroidal melanoma; perimetry revealed an absolute scotoma at the site of the tumour. The 48hour ${ }^{32} \mathrm{P}$-uptake test was positive, $+107 \%$. In view of the clinical diagnosis of malignant melanoma of the choroid the eye was enucleated. On histological examination the tumour proved to be a spindle B cell melanoma of the choroid.

The medical history was significant in that a pigmented skin lesion on his arm had been excised 2 years previously. Examination in the Department of Dermatology (Professor D. Suurmond) revealed a pigmented spot at the margin of the scar resulting from the previous removal. After excision histological examination showed the tumour to be a cutaneous malignant melanoma (Clark III). Two pigmented lesions were excised from the skin of the back; on histological examination they proved to be benign naevi. Six years later the patient is still in good health. There is no family history of malignancies, but a medical examination of the family members was not carried out.

\section{CASE 3}

A 59-year-old woman was referred because of metamorphopsia, and the patient had noticed a small scotoma when playing tennis. The cause was a $2 \mathrm{D}$ prominent tumour with a greyish, slightly pigmented aspect and located temporal to the posterior pole in the fundus of her right eye. Corrected visual acuity was $1 \cdot 0$. Perimetry revealed a small, absolute scotoma nasal to the fixation point. Fluorescein angiography showed a pattern typical of choroidal melanoma; the tumour was $5-6 \mathrm{~mm}$ in diameter according to ophthalmoscopic and ultrasonographic measurements. The 48 -hour ${ }^{32} \mathrm{P}$-uptake test was positive, $+93 \%$. Local irradiation was considered, but since the patient refused this treatment the eye was enucleated. On histological examination the tumour proved to be a spindle cell melanoma of the choroid. Seven years previously the patient's mother, aged 77 years, had been admitted to the ENT department of our hospital. She underwent surgery because of a large tumour in the nasal sinuses extending into all paranasal sinuses and into the left orbit. Complete removal of the tumour, which was found to be a malignant melanoma probably originating from the left ethmoidal sinus, was impossible. The patient died 8 months after the operation.

\section{Discussion}

Patients with hereditary forms of cancer may present a different clinical picture from that of patients with nonhereditary forms. The tumour may have an earlier age of onset and be bilateral, and the patient may have multiple primary cancers at different anatomical sites. ${ }^{1-4}$ Patient no. 1 is most unusual as a case of bilateral choroidal melanomas and multiple primary cutaneous malignant melanomas, while a study of his family has revealed the presence of the FAMMM syndrome. This syndrome derives its name from the clinical characteristics of multiple naevi, which vary in size (many $10 \mathrm{~mm}$ or more in diameter) and which may number as many as a hundred or more in certain patients. The naevi may vary in hue between tan, brown, pink, and red, occasionally with a variegated pattern, and are localised primarily on the upper part of the trunk or extremities, but may occur anywhere on the body; they have characteristic histological features. ${ }^{24}$ Patients with this syndrome are at risk of developing cutaneous melanomas and possibly also other primary malignancies. ${ }^{1-4}$ The FAMMM syndrome is inherited as an autosomal dominant trait.

The additional presence of independent bilateral choroidal melanomas in patient no. 1 is very rare. The incidence of unilateral uveal melanoma is $1: 70000$ to $1: 100000$; thus bilateral occurrence of uveal melanoma must be very rare. Only 22 cases have been reported,$^{5-8}$ to which we add one more. Jensen ${ }^{9}$ had no bilateral cases among his 295 melanoma patients. We found one in more than 250 patients.

The chance of the simultaneous but coincidental occurrence of primary cutaneous melanomas and a primary ocular melanoma in each of 2 patients (our cases 1 and 2) seems to be practically nil since these malignancies have an incidence of about 4:100000 and $1: 100000$ respectively. ${ }^{10}$ In addition 4 other cases 
of this condition have been described. In two of these ${ }^{1112}$ the tumours developed in patients with the FAMMM syndrome, as we observed in our patient no. 1. In the other 2 patients ${ }^{1314}$ (like our patient no. 2) the development of skin and uveal melanomas was not associated with the FAMMM syndrome. However, Bellet et al. ${ }^{12}$ suggest that the choroidal tumour described by Paton and Thomas ${ }^{13}$ should be redesignated as a choroidal naevus according to the reclassification of choroidal melanomas. ${ }^{15}$

The occurrence of intraocular and cutaneous melanomas in different members of a family has only been described in 3 families. Turkington ${ }^{16}$ mentions a brother and sister with an intraocular and a cutaneous melanoma respectively. Lynch and Krush ${ }^{17}$ reported on 2 sisters, one with an intraocular and one with a cutaneous melanoma, and on a father and son with an intraocular melanoma and a melanoma of the skin respectively. We add one more family: patient no. 3 with a choroidal melanoma had a mother who succumbed to an ethmoidal melanoma. To this could be added our patient no. 1 , since the family study revealed the presence of further malignant melanomas, atypical multiple moles, and other malignancies.

The frequency of the hereditary form of malignant melanoma of the skin was reported to lie between 0.4 and $12 \%$ of all melanomas depending on the intensity and mode of search. When intensive case finding was employed, $10.7 \%$ of 666 melanoma patients had a positive family history. ${ }^{18}$ Reports of the familial occurrence of intraocular melanomas, on the other hand, have been very rare, but perhaps they have not yet received proper attention. Only 11 families have been reported with this most frequently occurring intraocular tumour developing in 2 family members. ${ }^{18} 19$ Its occurrence in 3 successive generations has been reported only twice. ${ }^{2021}$ Lynch et al. ${ }^{22}$ found that out of 45 patients with intraocular melanoma there was only one familial occurrence (in brother and sister). We observed no familial occurrence in over 250 patients with intraocular melanoma. In the 11 families reported the intraocular melanomas were not associated with skin melanomas. Moreover in 28 families with skin melanomas not a single case of intraocular melanoma was found. ${ }^{23}$

The few reported instances of familial intraocular melanoma are compatible with autosomal dominant inheritance; the FAMMM syndrome, in which skin melanomas may develop, also follows an autosomal dominant pattern of inheritance. It is not possible to state whether the genes involved are identical, are alleles, or are situated at different loci. The simultaneous presence of intraocular and skin melanomas in 3 individuals with the FAMMM syndrome $^{1112}$ (including our own), which cannot be a coincidence as stated above, is good evidence for a single gene being responsible for both. This has also been suggested by Rodriguez-Sains. ${ }^{24}$

The presence of an intraocular malignancy in association with an extraocular malignancy is very unusual, since only 41 cases have been reported. ${ }^{212526}$ In cases of multiple primary malignancies involvement of the eye is very rare. Morgan et al. ${ }^{25}$ reported on a patient with 3 primary malignancies, including an ocular tumour. Pheasant et al. ${ }^{26}$ described a uveal melanoma as a fourth primary malignancy. Our patient no. 1 had 5 separate malignancies which may have been independent (although caused by a single gene defect): 3 skin melanomas and 2 choroidal melanomas. Ocular metastasis from a systemic melanoma, however, cannot be excluded. The data indicate that the risk that an additional tumour will develop in a patient suffering from a primary malignant uveal tumour is very small. In the case of patient no. 1, however, the existence of 4 malignancies should have led to careful follow-up of the remaining eye, as early detection of the melanoma in his second eye would perhaps have saved his vision by allowing time for irradiation treatment ${ }^{27}$ or local excision ${ }^{28}$ when the tumour was still small. Therefore ophthalmologists should be aware of the risk of development of new malignancies when treating a patient with an intraocular melanoma who has a positive family history or cutaneous signs of the FAMMM syndrome.

\section{References}

1 Lynch HT. Frichot BC. Lynch P. Lynch J. Guirgis HA. Family studies of malignant melanoma and associated cancer. Surg Gynecol Obstet 1975: 141: 1-6.

2 Lynch HT. Frichot BC, Lynch JF. Familial atypical multiple mole-melanoma syndrome. J Med Genet 1978; 15: 352-6.

3 Clarck WH Jr. Reimer RR. Greene MH, Ainsworth AM. Mastrangelo MJ. Origin of familial malignant melanomas from heritable melanocytic lesions-the B-K mole syndrome. Arch Dermatol 1978; 114: 732-8.

4 Lynch HT. Fusaro RM. Pester J, et al. Tumor spectrum in the FAMMM syndrome. Br J Cancer 1981; 44: 553-60.

5 Völcker HE. Naumann GOH. Multicentric primary malignant melanomas of the choroid: two separate malignant melanomas of the choroid and two uveal naevi in one eye. Br J Ophthalmol 1978; 62: 408-13.

6 Osborn EL. Walker JP, Weiter JJ. Bilateral choroidal melanomas: a case report. Ann Ophthalmol 1980; 12: 1154-5.

7 Gragoudas ES. Goitein M. Verhey L. Munzenreider J. Suits HD. Koehler A. Proton beam irradiation. An alternative to enucleation for intraocular melanomas. Ophthalmology 1980; 87: 571-81.

8 Lommatzsch PK. Hallermann D. von Domarus D. Treatment of bilateral choroidal malignant melanoma. Dev Ophthalmol 1981: 2: $105-13$.

9 Jensen OA. Malignant melanomas of the uvea in Denmark 1943-1952: a clinical, histopathological and prognostic study. Acta Ophthalmol (Kbh) 1963; suppl: 75. 
10 Cutler SJ, Young JL. Third National Cancer Survey: Incidence Data. National Cancer Institute Monograph No. 41. US Government Printing Office: 1975.

11 Abramson DH, Rodrigues-Sains RS, Rubman R. B-K Mole svndrome. Cutaneous and ocular malignant melanoma. Arch Ophthalmol 1980; 98: 1397-9.

12 Bellet RE. Shields JA. Soll DB, Bernardino EA. Primary choroidal and cutaneous melanomas occurring in a patient with the B-K mole syndrome phenotype. Am J Ophthalmol 1980; 89: 567-70.

13 Paton D. Thomas LB. Simultaneous occurrence of primary malignant melanomas of the eye and the skin. Arch Ophthalmol 1959; 62: 645-52.

14 Augsburger JJ, Shields JA, Frank PE, Mastrangelo MJ. Diffuse primary malignant melanoma after prior primary cutaneous malignant melanoma. Arch Ophthalmol 1980; 98: 1261-4.

15 McLean IW, Zimmerman LE, Evans RM. Reappraisal of Callander's spindle: a type of malignant melanoma of the choroid and ciliary body. Am J Ophthalmol 1978; 86: 557-64.

16 Turkington RW. Familial factor in malignant melanoma. JAMA 1965; 192: 77-82.

17 Lynch HT, Krush AJ. Heredity and malignant melanoma: implications for early cancer detection. Can Med Assoc J 1968; 99: 17-21.

18 Greene MH. Fraumeni JF Jr. The hereditary variant of malignant melanoma. In: Clark WH, Goldman LI, Mastrangelo MJ, eds. Human Malignant Melanoma. New York: Grune and Stratton. 1979: 139-66.
19 Martijn H. Oldhoff J, Oosterhuis JW. Schraffordt Koops H. Vermey A. Familiaire maligne melanomen. Ned Tijdschr Geneeskd 1981: 135: 1194-8.

20 Davenport RC. A family history of choroidal sarcoma. $\mathrm{Br} \mathrm{J}$ Opthalmol 1927; 11: 443-5.

21 Walker JP. Weiter JJ, Albert DM, Osborn EL. Weichselbaum RR. Uveal malignant melanoma in three generations of the same family. Am J Ophthalmol 1979; 88: 723-6.

22 Lvnch HT. Anderson DE. Krush AJ. Heredity and intraocular malignant melanoma. Cancer 1968; 21: 119-25.

23 Anderson DE. Smith JL Jr, McBride CM. Hereditary aspects of malignant melanoma. JAMA 1967; 200: 741-6.

24 Rodriguez-Sains RS. Are concurrent or subsequent malignant melanomas in the skin and eye related or coincidental? $J$ Dermatol Surg Oncol 1980; 6: 915-8.

25 Morgan SS. Heidenry R. Bowen SF Jr. Malignant melanoma of the iris and ciliary body occurring as a third primary malignancy. Am J Ophthalmol 1973; 76: 26-9.

26 Pheasant TR. Michelson JB. Shields JA. Pro JM. Uveal melanoma occurring as a fourth primary malignancy: case report. Ann Ophthalmol 1979; 11: 625-7.

27 Lommatzsch PK. Radiotherapie der intraokularen Tumoren ins besondere bei Aderhautmelanoma. Klin Monatsbl Augenheilkd 1979; 174: 948-58.

28 Foulds WS. Local excision of choroidal melanomas. Trans Ophthalmol Soc UK 1974: 93: 343-6. 